\title{
Understanding the Complex Adoption Behavior of Cloud Services by SMEs Based on Complexity Theory: A Fuzzy Sets Qualitative Comparative Analysis (fsQCA)
}

\author{
Ge Zhang $(\mathbb{D}$, Weijie Wang $(\mathbb{D}$, and Yikai Liang $(\mathbb{D}$ \\ School of Management Science and Engineering, Shandong University of Finance and Economics, Jinan 250014, China \\ Correspondence should be addressed to Yikai Liang; yikailiang@qq.com
}

Received 13 January 2021; Revised 17 March 2021; Accepted 19 March 2021; Published 2 April 2021

Academic Editor: Lei Xie

Copyright (c) $2021 \mathrm{Ge}$ Zhang et al. This is an open access article distributed under the Creative Commons Attribution License, which permits unrestricted use, distribution, and reproduction in any medium, provided the original work is properly cited.

\begin{abstract}
To survive in a competitive environment, small and medium enterprises (SMEs) have had to adapt to the digital environment in order to adjust to customer needs globally, particularly in the post-COVID-19 world. The advantages of cloud computing (e.g., flexibility, scalability, and low entry cost) provide opportunities for SMEs with a restricted budget and limited resources. To understand how SMEs adopt cloud computing in a complex digital environment, this study examines how antecedents combine with each other to explain the high adoption of cloud computing. From the perspectives of holism and set theory, we draw on complexity and configuration theories, present a conceptual model including seven antecedents based on the technology-organization-environment framework, and conduct an asymmetric fuzzy-set qualitative comparative analysis. Through an empirical study with 123 Chinese companies, we identify nine combinations (configurations) of determinant antecedents that lead to the high adoption of cloud computing. The results show that none of the factors are indispensable to explain a high adoption on their own; instead, they are insufficient but necessary parts of the causal combinations that explain a high adoption. This study contributes to the literature on cloud computing adoption by extending current knowledge on how antecedents combine to increase the adoption and identify specific patterns of SMEs for whom these factors are essential and greatly influence their adoption.
\end{abstract}

\section{Introduction}

Small and medium enterprises (SMEs) use digital technologies in the current digital era, such as artificial intelligence, smart technologies, and cloud technology, to grow their online businesses alongside their offline operations. The digital environment provides numerous opportunities for entrepreneurs who start and run SMEs to impact and grow their businesses. To survive in a turbulent competitive environment, SMEs have had to adapt to the digital environment to adjust to customer needs globally, particularly in a post-COVID-19 world. Therefore, there is a strong need for digital technologies to improve the business performance, cost advantages, and competitive advantages with a restricted budget and limited resources.
As a representative emerging digital technology, cloud computing has become an important information technology (IT) development trend in recent years. Cloud computing is considered a transformation of IT resources and the service delivery paradigm, and promises to deliver IT resources as a utility, similar to water, electricity, gas, and telephony services [1]. An increasing number of well-known IT service providers have begun to provide cloud services, such as Amazon (Elastic Computing Cloud), Google (App Engine), and Microsoft (Azure). Cloud computing can transform business processes, reduce IT expenditures, deliver real-time applications, provide access to ubiquitous storage, and have unlimited computing power and the potential for market information mobilization. It has therefore been used in various fields such as e-commerce, e-government, and customer relationship management [2-6]. 
The advantages of cloud computing services (e.g., flexibility, scalability, and low entry cost) also provide opportunities for SMEs. These opportunities can enable SMEs to improve IT capability with relatively low transaction and switching costs, and to formulate quality IT strategies allowing SMEs to develop within the new technological paradigm shift [7]. Small businesses can improve their operations and productivity enormously by moving to the cloud. Doing so will increase their revenue, thereby setting them ahead of the competition. In addition, the governments of many countries have issued relevant policies to encourage domestic enterprises to use cloud services. For example, the State Council of China issued its "Opinions on Promoting the Innovative Development of Cloud Computing and Cultivating New Types of Information Industry" in January 2015. Although the adoption of cloud services can bring about many benefits to SMEs, not all SMEs are eager to adopt cloud services and are still on the sidelines owing to various challenges, such as privacy and data security issues, a lack of uniform standards for the cloud services industry, and an inadequate regulation of cloud services [8-11]. In particular, the size and structure of SMEs often make them face specific challenges. Although the adoption of cloud services can increase their competitive advantage, it also involves the consumption of funds. Therefore, SMEs need to be extremely cautious when making decisions on the adoption of cloud services [12]. Therefore, in response to the call of the country to encourage enterprises to adopt cloud services, thereby accelerating the digital transformation of enterprises and promoting the development of the cloud computing industry, it is important to explore ways to encourage SMEs to adopt cloud computing and take relevant targeted measures.

Numerous studies in this area have used conventional regression-based quantitative methods, such as multiple regression analysis and structural equation modeling, to explore the factors that affect the adoption of cloud services by an enterprise. These methods assume that relations between variables are symmetric, and adopt an isolated analytical perspective on variables, focusing on exploring the marginal "net effect" of a single variable or a few variables on the adoption of cloud services. It is difficult to explain the interdependence of variables and the complex cause-effect relationships on how variables' configurations affect the results. However, as in real life, it is a common phenomenon that the conditions occurring in management practice are interdependent rather than independent. There are few studies on the complex cause-effect relationship between each antecedent variable (e.g., interdependence) or on the different casual configurations required for enterprises to adopt cloud services.

To address such gaps in the literature, we start from the perspectives of holism and set theory, taking 123 SMEs with a high degree of informatization as the empirical research object, using the qualitative comparative analysis method initiated by Ragin [13] to study the configurations of determinants for enterprises adopting cloud services, and to explore the conditions under which enterprises are more inclined to adopt such services. The results of this research will improve theories on cloud service adoption and promote the application of qualitative comparative analysis in the field of information systems (IS). At the same time, theoretical guidance for SMEs to formulate better IT strategies and cloud service providers to provide products that better meet market needs, formulate specific sales strategies, and formulate more scientific policies to promote the development of the cloud computing industry is provided. At the same time, it provides theoretical guidance for SMEs, cloud service providers, and government to formulate better IT strategies, provide products that better meet market needs, and make more scientific policies to promote the development of the cloud computing industry, respectively.

\section{Literature Review}

2.1. Cloud Services and Their Adoption. Cloud computing is defined as "a model for enabling ubiquitous, convenient, ondemand network access to a shared pool of configurable computing resources (e.g., networks, servers, storage, applications, and services) that can be rapidly provisioned and released with minimal management effort or service provider interaction" by the National Institute of Standards and Technology (NIST) [14]. Cloud computing refers to both applications delivered as services over the Internet and hardware and systems software in a data center that provide such services [2].

Cloud computing can bring about many benefits to an enterprise and is an innovative computing model that enables SMEs to obtain complex technologies without investing much money. Enterprises can take advantage of the flexibility of cloud computing to increase computing resources as demand increases, which enables enterprises to plan far ahead for provisioning [15, 16]. Computational resources are stored in the resource pool, and users can access these scalable and adjustable resources virtually [15]. These computing resources can be used automatically, and their use does not require any organizational interaction $[14,15]$. However, not all enterprises are willing to adopt cloud services owing to various challenges, such as privacy and data security issues, a lack of uniform standards for the cloud services industry, and inadequate regulations [8-11]. Therefore, to accelerate the development of the cloud computing industry, numerous studies have used technology adoption theories to explore the determinants of intention and behavior to adopt cloud services. Table 1 lists the empirical studies on cloud service adoption over the past 10 years.

As shown in Table 1, the existing literature mainly uses a regression analysis and structural equation modeling to study the independent effects of factors, such as technology, organization, and environment, on the adoption and assimilation of cloud services in enterprises and medical and educational industries. Few studies have investigated the interdependence between multiple factors. However, to further reveal the influence mechanism of the adoption of cloud services by an enterprise, it is necessary to explore the complex interactions of multiple factors from a holistic perspective. To fill in this gap, we adopt a fuzzy-set 
TABle 1: Empirical research on cloud service adoption.

\begin{tabular}{llll}
\hline Resources & Theory basis & Methodology & Adoption (DV) \\
\hline$[17]$ & $\begin{array}{l}\text { No specific } \\
\text { theory is used }\end{array}$ & PLS & Intention to adopt CC \\
{$[18]$} & TAM & PLS & Behavioral intention \\
{$[19]$} & TOE, DOI, INT & $\begin{array}{l}\text { No specific methodology is } \\
\text { used. }\end{array}$ & Intention to adopt cloud
\end{tabular}

[5] TOE Regression analysis $\quad$ CC adoption

$$
\text { TAM3 }
$$

Path analysis

Actual usage of CC

[21] TOE

$$
\text { SEM }
$$

Intention to adopt CC

No specific theory is used

PLS

$$
\text { TOE, DOI }
$$

SEM

CC adoption

\section{TOE}

TOE

$$
\text { SEM }
$$

Cloud adoption intention

TOE

Semistructured interviews

Intention to adopt cloud
TOE, DOI
SEM

PLS

Binomial test, fuzzy AHP
Attitude toward SaaS, intention to use SaaS

CC adoption
Perceived accessibility, perceived scalability, perceived cost-effectiveness, perceived lack of security

Social influence, attitude toward mobile innovation, perceived benefits, perceived usefulness, perceived ease of use, behavioral intention, marketing efforts, security, and trust Availability, reliability, security, privacy, trust, relative advantage, compatibility, complexity, top management support, organization size, technology readiness, compliance with regulations, competitive pressure, trading partner pressure, physical location

Relative advantage, complexity, compatibility, top management support, firm size, technology readiness, competitive pressure, trading partner pressure

Access to software, ease of travel, personal innovativeness, technology anxiety, instructor support, reliability, usefulness, ease of use Cloud security, compatibility, reliability and availability, extendibility of existing APPs to cloud, compliance policy, lack of IT standards, business scalability, cost flexibility, market adaptability, hidden complexity, share best practices, adopter's style

Reliability, ease of use and convenience, cost reduction, sharing and collaboration, security and privacy

Relative advantage, complexity, compatibility, security concerns, cost savings, technology readiness, top management support, firm size, competitive pressure, regulatory support CIO innovativeness, perceived technical competence, data security, complexity, compatibility, cost, relative advantage, top management's support, adequate resource, benefits, government policy, perceived industry pressure

Perceived benefits, business concerns, IT capability, external pressure

Availability, reliability, security, privacy, trust, relative advantage, compatibility, complexity, top management support, organization size, technology readiness, compliance with regulations, competitive pressure, trading partner pressure, physical location

IT infrastructure, top management support, relative advantage, simplicity, compatibility, experience ability, competitor pressure, partner pressure

Relative advantage, complexity, compatibility, management support, vendor lock, data concern, government regulation, peer pressure Relative advantage, competitive pressure, security and privacy, sharing and collaboration culture, social influence, compatibility, IT resource, observability, complexity, trialability 
TABle 1: Continued.

\begin{tabular}{|c|c|c|c|c|}
\hline Resources & Theory basis & Methodology & Adoption (DV) & Determinants (IV) \\
\hline [7] & TOE & SEM & $\begin{array}{l}\text { Cloud service } \\
\text { transformation intention }\end{array}$ & $\begin{array}{l}\text { Reliability, information security, institutional } \\
\text { pressure, structure assurance, vendor scarcity, } \\
\text { size, international scope, IT competence, } \\
\text { entrepreneurship }\end{array}$ \\
\hline$[30]$ & $\begin{array}{l}\text { No specific } \\
\text { theory is used }\end{array}$ & $\begin{array}{l}\text { Hierarchical multiple } \\
\text { regression analysis }\end{array}$ & $\begin{array}{l}\text { Cloud service adoption } \\
\text { intention }\end{array}$ & $\begin{array}{l}\text { Relative advantage, compatibility, observability, } \\
\text { trialability, perceived complexity, subjective } \\
\text { norms, new technology self-efficacy, network } \\
\text { externality }\end{array}$ \\
\hline$[31]$ & TOE & Analysis of variance, PLS & $\begin{array}{l}\text { A firm's intention to adopt } \\
\text { CC services }\end{array}$ & $\begin{array}{l}\text { Relative advantage, ease of use, compatibility, } \\
\text { trialability, observability; security, firm size, } \\
\text { global scope, financial costs, satisfaction with } \\
\text { existing IS, competition intensity, regulatory } \\
\text { environment }\end{array}$ \\
\hline$[32]$ & TAM & Quantitative research & $\begin{array}{l}\text { Respondents' intention to } \\
\text { use CC }\end{array}$ & $\begin{array}{l}\text { Perceived ease of use, personal innovativeness, } \\
\text { threat and high scores in respondents' challenge, } \\
\text { self-efficacy, openness to experience, computer } \\
\text { competence, and in social media use }\end{array}$ \\
\hline [33] & $\begin{array}{l}\text { No specific } \\
\text { theory is used }\end{array}$ & Structural-equations model & Adoption on public CC & $\begin{array}{l}\text { Alignment, adaptation, security, cost- } \\
\text { effectiveness, operational risk, IT compliance, } \\
\text { management/controlling power }\end{array}$ \\
\hline [34] & $\begin{array}{l}\text { SLA, DOI, trust } \\
\text { theory, TAM }\end{array}$ & $\begin{array}{l}\text { Descriptive analysis, CFA, } \\
\text { correlation analysis, fsQCA, } \\
\text { SEM }\end{array}$ & $\begin{array}{l}\text { Cloud service adoption } \\
\text { intention }\end{array}$ & $\begin{array}{l}\text { Trust of firms concerning cloud services, } \\
\text { perceived usefulness of loud service, trust in } \\
\text { cloud service, foundation characteristics specific } \\
\text { to cloud service, perceived compatibility } \\
\text { regarding cloud service, perceived relative } \\
\text { advantage regarding cloud services }\end{array}$ \\
\hline$[35]$ & DOI, TAM & SEM & $\begin{array}{l}\text { Intention to adopt CC, } \\
\text { actual usage of CC }\end{array}$ & $\begin{array}{l}\text { Awareness, cost-effectiveness, risk, data security, } \\
\text { infrastructure, relative advantage, compatibility, } \\
\text { complexity, observability, trialability, results } \\
\text { demonstrable, ease of use, usefulness, } \\
\text { sociocultural }\end{array}$ \\
\hline [36] & TOE, DOI, INT & PLS & $\begin{array}{l}\text { Three stage of SaaS diffusion: } \\
\text { Intention, adoption, } \\
\text { routinization }\end{array}$ & $\begin{array}{l}\text { Relative advantage, compatibility, complexity, } \\
\text { technology competence, top management } \\
\text { support, coercive pressures, normative } \\
\text { pressures, mimetic pressures }\end{array}$ \\
\hline [15] & $\begin{array}{l}\text { No specific } \\
\text { theory is used }\end{array}$ & SEM, EFA, CFA & CC adoption & $\begin{array}{l}\text { Security, need, cost saving, supplier availability, } \\
\text { integration, maintenance, virtualization, } \\
\text { reliability, performance }\end{array}$ \\
\hline [37] & $\begin{array}{l}\text { TOE, INT, } \\
\text { PVT }\end{array}$ & SEM & $\begin{array}{l}\text { The intention to adopt SaaS, } \\
\text { the adoption of SaaS }\end{array}$ & $\begin{array}{l}\text { Representation capability of SaaS, reach } \\
\text { capability of SaaS, monitoring capability of SaaS, } \\
\text { technology competence, top management } \\
\text { support, coercive pressure, normative pressure, } \\
\text { mimetic pressures }\end{array}$ \\
\hline$[38]$ & DOI, TAM & SPSS, SEM & $\begin{array}{l}\text { The intent to adopt CC, } \\
\text { actual usage of CC }\end{array}$ & $\begin{array}{l}\text { Awareness, upfront cost saving, running cost, } \\
\text { risk, data security, availability of good } \\
\text { information and communications technology } \\
\text { infrastructure, relative advantage, compatibility, } \\
\text { complexity, observability, trialability, results } \\
\text { demonstrable, ease of use, usefulness, } \\
\text { sociocultural factors, the age of the university, } \\
\text { the size of the university, the location of the } \\
\text { university, the age of university information and } \\
\text { communications technology experts and } \\
\text { decision-makers }\end{array}$ \\
\hline [39] & TAM & SEM & Behavioral intention to use & $\begin{array}{l}\text { Perceived usefulness, perceived ease of use, top } \\
\text { management support, training, communication, } \\
\text { technological complexity, organization size }\end{array}$ \\
\hline
\end{tabular}


TABLE 1: Continued.

\begin{tabular}{|c|c|c|c|c|}
\hline Resources & Theory basis & Methodology & Adoption (DV) & Determinants (IV) \\
\hline$[40]$ & $\begin{array}{l}\text { No specific } \\
\text { theory is used }\end{array}$ & SEM, CFA & The level of CC adoption & $\begin{array}{l}\text { R\&D institutions over an organization, the } \\
\text { influence of technology providers, public } \\
\text { administration on a given organization, } \\
\text { managers' awareness of killer applications based } \\
\text { on cloud computing, managers' awareness of } \\
\text { success cases in cloud computing }\end{array}$ \\
\hline [41] & $\begin{array}{l}\text { TOE, grounded } \\
\text { theory }\end{array}$ & Coding & $\begin{array}{l}\text { E-Government cloud } \\
\text { adoption }\end{array}$ & $\begin{array}{l}\text { Comparative advantage, technological concern, } \\
\text { cloud provider characteristic, cloud provider } \\
\text { competence, cloud provider presence, top } \\
\text { management support, organization inertia, the } \\
\text { scale and complexity of information resource, } \\
\text { policy and regulation, industry standards, } \\
\text { competition pressure, requirement of citizen, } \\
\text { best practice, financial fund, initial trust, } \\
\text { perceived benefit-based trust }\end{array}$ \\
\hline$[42]$ & TOE & $\begin{array}{l}\text { SEM, artificial neural } \\
\text { network }\end{array}$ & CC adoption & $\begin{array}{l}\text { Perceived IT security risk, risk analysis, } \\
\text { technology innovation, usage of technology, } \\
\text { industry usage, trust, management style }\end{array}$ \\
\hline$[43]$ & TOE & PLS & SaaS adoption & $\begin{array}{l}\text { Coercive pressures, normative pressures, } \\
\text { mimetic pressures, technology competence, top } \\
\text { management support }\end{array}$ \\
\hline$[12]$ & TOE, DOI & $\begin{array}{l}\text { Quantitative analysis, } \\
\text { logistic regression }\end{array}$ & CC adoption & $\begin{array}{l}\text { Manager cloud computing expertise, employee's } \\
\text { know-how, perceived business benefit, cost } \\
\text { reduction, security and privacy, cooperation } \\
\text { with cloud providers, the government support, } \\
\text { employee's information access, manager's } \\
\text { innovation capacity, trialability }\end{array}$ \\
\hline
\end{tabular}

CC, Cloud computing; DV, Dependent Variable; IV, Independent Variable; SEM, Structural-equations model; EFA, Exploratory factor analysis; CFA, Confirmatory factor analysis; PLS, Partial Least Squares; TAM, Technology Acceptance Model; TOE, Technology-Organization-Environment; DOI, Diffusion of Innovation; INT, Institutional Theory; PVT, Process Virtualization Theory.

qualitative comparative analysis (fsQCA) method based on the set theory to study the main configuration of determinants of cloud service adoption by SMEs, and analyze the joint action and interaction mechanism of various factors on the cloud service adoption by SMEs both comprehensively and systematically.

2.2. TOE Framework. The technology-organization-environment (TOE) framework was proposed to explain the innovation process in the context of an organization [44]. It considers three contexts that influence the adoption of innovation by an organization: technology, organization, and environment context [44]. The TOE framework has been applied to research on the adoption of various technologies $[43,45,46]$. It has been applied many times to study cloud service adoption at the enterprise level $[5,25,31,47]$. The technology context refers to the internal and external technologies related to the organization $[5,23,36]$ and technologies that affect the adoption process [31]. Organizational context refers to the descriptive characteristics of an enterprise, such as enterprise size, management structure, degree of centralization, and quality of human resources $[5,23,31,36,44,48]$. The environment context includes market elements, competitors, regulatory environments, and government policies $[5,23,36,44]$. The TOE framework is consistent with the Diffusion of Innovation (DOI) proposed by Roger et al. The DOI takes the five technical characteristics of relative advantage, complexity, compatibility, observability, and trialability, as determinants of innovation adoption [49-51]. Some researchers in the IS field believe that the institutional (INT) theory can strengthen the environmental context of the TOE framework [48, 52-54]. The INT theory defines different institutional pressures, such as the coercive pressure, normative pressure, and mimetic pressure [55]. Institutional pressure has proven to be an essential determinant of innovation adoption, particularly in remote systems such as SaaS $[43,56]$. However, the DOI and INT theories only consider unilateral factors that affect the process of innovation adoption. Combining DOI, INT theory, and the TOE framework can compensate for this deficiency and further improve the explanatory capability of the model [23]. Many previous studies have adopted integrated models to explore the adoption of various innovations $[12,23,36]$.

\section{Research Model and Antecedents of Cloud Service Adoption}

3.1. Research Model. Although previous studies have demonstrated that various factors can influence cloud service adoption, almost all factors can be classified into technological, organizational, or environmental contexts. Moreover, with the development of cloud services, and an 
understanding of what they provide, an increasing number of cloud service providers have been adjusting and improving their related technologies to attract enterprises to adopt such services [40]. Moreover, with an increasing number of enterprises adopting cloud services, cloud service providers are emerging in the market. The characteristics of cloud service providers will also influence other antecedents to a certain extent. For example, the technical and management service capabilities of cloud service providers can influence the relative advantages of cloud services. Therefore, provider factors are also essential factors for enterprises to consider when making cloud service adoption decisions [41]. Based on the above analysis, combining the characteristics of cloud services and expanding on the three dimensions of technology, organization, and environment that have been clearly defined in the TOE framework, we propose a cloud service adoption model of SMEs with four different dimensions, namely, technology-organization-environment-provider, and empirically test the relevant antecedents. The research model is shown in Figure 1.

\subsection{Antecedents of Cloud Service Adoption}

3.2.1. Technology Context. The two-factor theory of technology adoption recently appeared in the IS field, which is the inheritance and development of Herzberg's two-factor theory of motivation [57-60]. The two-factor theory divides the factors that affect the user's will into promoting factors (motivators) and inhibiting factors (hygiene) [59]. In the IS field, promoting factors refer to factors that promote users to adopt a specific product or service, whereas inhibiting factors refer to factors that hinder users from adopting them $[59,60]$. The two-factor theory states that promoting and inhibiting factors are not opposed to each other, and independently affect the user's will $[59,61]$. The adoption of cloud services by enterprises is an act of adopting new technologies or services, and technical characteristics are the key factors that influence the adoption of innovative technologies by organizations. As an innovative technology, the relative advantage of cloud services can bring competitiveness to an enterprise. However, because of security issues, enterprises can also be exposed to certain risks. Therefore, based on the two-factor theory, enterprises need to consider both the relative advantages and perceived security risks of cloud services in terms of technical characteristics when making cloud service adoption decisions.

(i) Relative Advantage. The relative advantage is defined as "the degree to which an innovation is perceived as being better than its precursor" [62]. Existing studies suggest a positive correlation between relative advantage and IT adoption [28, 29, 31]. When enterprises perceive that an innovative technology has relative advantages, the possibility of adopting this technology will increase [63, 64]. Cloud services provide many advantages for adopters, including flexibility, scalability, a low entry cost, pay-per-use, portability, ease of installation and maintenance, and run analyses through the Internet $[2,3,25]$. Enterprises are usually willing to adopt new technologies with the advantage of improving the business performance and efficiency. Therefore, the relative advantages of cloud services are considered essential variables for their adoption by an enterprise.

(ii) Perceived Security Risk. Perceived security risk refers to the risk that users perceive when they believe that cloud service adoption will hinder an organization's performance $[42,65]$. Cloud services are the integration of storage and computing in a shared multi-user environment. Because they cannot fully understand and determine potential security risks, enterprises add security considerations when deciding whether to adopt a cloud service [66-68]. The main security risks perceived by an enterprise in using a cloud service come from data security issues, including a malicious manipulation of private data, a risk of disclosure of private information, and a reduced auditability of the enterprise data. These security risks will cause economic losses to an enterprise and lead to a decline in its prestige and trust from the public to a certain extent. Therefore, we believe that the perceived security risks that cloud services bring to an enterprise will affect an enterprise with its intention to adopt a cloud service.

\subsubsection{Organization Context. Organizational factors include} the organizational characteristics and the support of available resources within the organization, which is an internal situational condition that promotes or restricts the adoption of innovative technologies within the organization. As an innovative technology, whether an enterprise adopts a cloud service and includes it in its management decision depends mostly on the top management's attitude and actions inside the enterprise. At the same time, IT competency of an enterprise also promotes or restricts its interest to adopt cloud services to a certain extent. Therefore, this study takes top management support and IT competence as essential variables that influence the adoption of cloud services by an enterprise at the organizational level.

(i) Top Management Support. Top management support has proven to be a necessary condition for overcoming organizational resistance to change and ensuring a successful IT implementation [69]. Top management support is the vision, support, and commitment provided by top management to create an ideal environment for adopting a cloud service [70]. Top management support is particularly crucial for the adoption of technology in SMEs, where the CEO or equivalent personnel often has the final say over the organization's information and communications technology strategy and resulting investments [39, 71]. When top management recognizes the advantages of cloud services, it may allocate necessary resources for adopting a cloud service and encourage its use by the employees; conversely, when top management does not recognize the benefits of cloud services to the enterprise, it will refuse to adopt such services [23]. Therefore, top management support is also considered an essential factor influencing the adoption of cloud services by an enterprise. 


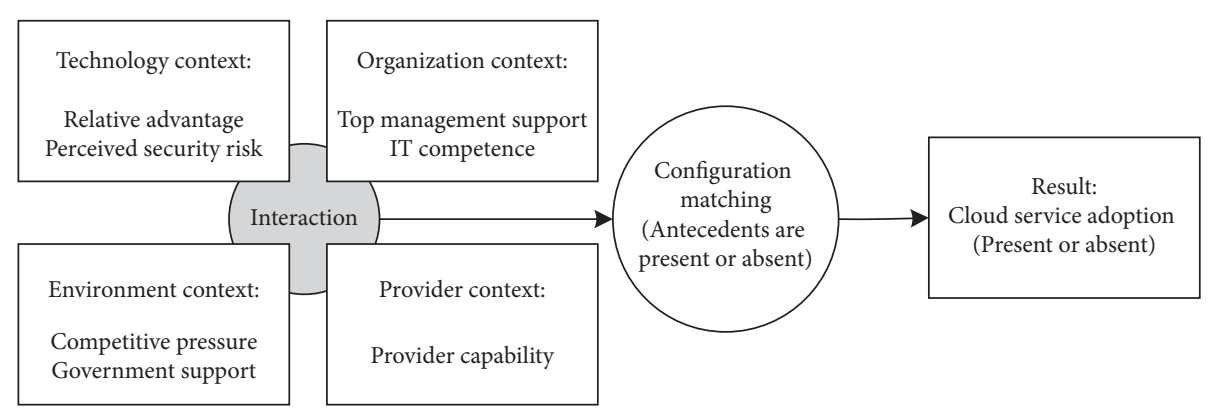

FIgURE 1: Research model.

(ii) IT Competence. IT competence refers to the technologies available in the organization, such as IT infrastructure and IT professionals [72]. IT infrastructure refers to installed platforms that can complement or be replaced by a new technology solution $[23,37]$. IT professionals are employees who have the expertise required to implement cloud services [36]. Existing studies have found that it is an essential factor influencing IT adoption [36, 37, 43]. To improve the IT performance, SMEs with weaker IT competence may have more incentives to adopt cloud services. Therefore, we believe that the IT competence of an enterprise will affect its willingness to adopt a cloud service.

3.2.3. Environment Context. Environmental factors refer to external constraints and feasible conditions for organizations to adopt innovative technologies. Any decision made by an enterprise will be affected by the social environment in which the enterprise is located. We believe that two factors at the environmental level-competitive pressure and government support-affect the cloud service adoption decisions of an enterprise.

(i) Competitive Pressure. Competitive pressure refers to the pressure that enterprises experience from competitors in the industry $[5,73,74]$ and has been proven to be an essential factor in technology diffusion in the literature on innovation diffusion [23]. SMEs are largely available, have weak funds, and have poor risk resistance, and thus are more likely to feel pressure from competitors and follow them in the use of new technologies. By adopting cloud services, enterprises can better understand market visibility, collect data more accurately, and achieve a higher operational efficiency, which will lead to more profits for the enterprise $[5,75]$; therefore, enterprises can better continue to operate in industry competition. We believe that competitive pressure is an essential variable for enterprises adopting cloud services.

(ii) Government Support. Government support means that the government plays a promotional role in the strategic plan and business operations of an enterprise by providing political, economic, and social resources [76]. It includes direct investment, the establishment of relevant funds, the formulation of privilege policies, and the provisioning of specific guidance. SMEs have weak funds, poor fund-raising capabilities, and poor risk resistance, whereas government support can be regarded as a form of social capital that can help enterprises overcome problems such as resource shortages [77]. To accelerate the development of science and technology, many countries have issued relevant policies to promote the development of the cloud computing industry and provide financial support for some cloud computing projects. For example, the State Council of China issued the "Opinions on Promoting the Innovative Development of Cloud Computing and Cultivating New Types of Information Industry" in January 2015, and the Ministry of Industry and Information Technology issued the "Three-year Action Plan for Cloud Computing Development (2017-2019)" in April 2017. Some enterprises that have successfully adopted cloud computing will be rated as benchmark enterprises, with improved social reputation and social status, as well as receiving more political, economic, and social resources [78]. Therefore, with the government's support, companies can establish a good corporate image by adopting cloud services, and to a certain extent, gain more economic and social benefits. Given this, government support is considered an essential factor that influences enterprises to adopt cloud services.

3.2.4. Provider Context. With the development of cloud services and an understanding of cloud services of an enterprise, an increasing number of cloud service providers have been adjusting and improving their related technologies to attract enterprises to adopt cloud services [40]. Furthermore, as an increasing number of enterprises adopt cloud services, cloud service providers are emerging in the market. Therefore, we also consider the factors of the cloud providers and believe that their capability is also an essential factor for enterprises to consider when making cloud service adoption decisions.

(i) Provider Capability. Cloud provider capabilities refer to the technical service capabilities of the provider and the management service capabilities required to virtually complete work tasks in specific areas, such as computing capabilities, the ability to reasonably take security measures and disaster recovery measures, and the ability to standardize service standards $[41,63,79,80]$. Cloud service providers with higher capabilities can usually better protect the private data of an enterprise and achieve higher technological advancement and service standardization. In the 
face of such cloud service providers, enterprises will be more inclined to adopt cloud services to improve the operational efficiency, the security of enterprise data, and the standardization of business processes, and reduce costs in all aspects of the enterprise. Therefore, we believe that the capabilities of cloud providers affect the adoption of cloud services by an enterprise.

\section{Methodology}

4.1. Data Collection. The variables in this study were measured using a 5-point Likert scale. To ensure the reliability and validity of the scale, the measurements of the variables should refer to existing mature scales as much as possible, while comprehensively considering the context of Chinese enterprises adopting cloud services. Because some of the reference items were originally in English, according to the translation and back-translation procedures, the students of this major translated the English items into Chinese, and then several master's students back-translated the items into English. This process ensured the accuracy of the questionnaire translation through a comparison. We contacted organizations such as the Shandong CIO Union to invite their members to help us fill out the questionnaires. These enterprises have a relatively high degree of informatization, and 240 questionnaires were distributed to enterprises in China through an online survey by Wenjuanxing (http:// www.wenjuan.com). The questionnaires were filled out by grassroots/middle-level/senior managers of the enterprise information department. A total of 123 valid questionnaires were returned, with an effective recovery rate of $51.25 \%$. The descriptive statistics of the sample are shown in Table 2.

4.2. Reliability and Validity Measures. We used Smart PLS software (version 3.0) to conduct a partial least squares analysis on the data. Reliability describes the internal consistency of the measurement results. Reliability testing was measured using Cronbach's $\alpha$ (CA) and composite reliability (CR). Through a calculation, the CA and CR values of each variable are greater than 0.7 , and 0.8 , respectively, indicating that each variable has good internal consistency and that the measurement model has good reliability. Validity includes content validity and construct validity, and construct validity is measured by convergent and discriminant validity. Convergent validity is used to judge whether different observed variables can be used to measure the same latent variable. The criterion is the average variance extracted (AVE) of the latent variable and the factor loading of the construct. Through the calculation, all AVE values and factor loading values are greater than 0.5 , and 0.7 , respectively, indicating that the measurement model has a good convergent validity. Discriminant validity refers to whether there are significant differences between latent variables. If the square root of the average variance extracted from a variable is greater than the correlation coefficient between the variable and the other variables, the discriminant validity of this variable is good. The calculation shows that the measurement model has high discriminant validity.
4.3. QCA and Data Analysis. Traditional statistical methods (e.g., regression analysis) mainly study the net effect of independent variables on dependent variables, and it is difficult to explain the interdependence between independent variables. With a qualitative comparative analysis (QCA), which is a case-study-oriented method, it is believed that the result occurs based on the interaction of related elements. The combination of each element is called the configuration [81-84]. A QCA is divided into two methods: a clear-set QCA and a fuzzy-set QCA. The value of a variable in a clear-set QCA is zero or 1, and in a fuzzy-set QCA, it is a real number between these same values. Because fsQCA is more distinguishable than a clear-set QCA, fsQCA was used in this study [83]. Similar to the significance level and coefficient of determination in a regression analysis, fsQCA uses the consistency and coverage proposed by Ragin to test the relationship between independent and dependent variables. Consistency can be used to determine whether an independent variable is a sufficient or necessary condition for a dependent variable [82]. When the consistency is greater than 0.8 , the independent variable $X$ is considered a sufficient condition for the dependent variable $Y$, and when the consistency is greater than 0.9 , the independent variable $X$ can be considered as a necessary condition for the dependent variable $Y$. Coverage reflects the explanatory degree of the model. Based on this, we select the relative advantage, perceived security risk, top management support, IT capability, competitive pressure, government support, and provider capability to study the interaction mechanism between variables. A complete QCA analysis process includes a theoretical analysis and the extraction of antecedents, data collection, variable recalibration, selection of case frequency and consistency thresholds, construction of a truth table, a standardized QCA, and the reporting of results using QCA symbols.

We first need to calibrate the measured variables and convert them into sets [81]. The calibration of variables requires three thresholds to be set based on theoretical knowledge and actual conditions: a full-membership threshold, an intermediate membership threshold, and a full nonmembership threshold. The eight variables selected in this study were measured using 2-4 items. The score of each variable for each item was obtained according to the 5-point Likert scale scoring standard, and the average score of each variable was calculated as the final score. We set the maximum and minimum scores of each variable as the full-membership threshold and full nonmembership threshold, respectively. The mean values of the scores were set as the intermediate membership threshold for variables with little difference between the mean and median scores. The mean and median scores of some variables were significantly different, whereas the median scores were 4.33 , the samples with a score of 4.33 are more than $20 \%$ of the total sample. Therefore, the intermediate membership thresholds of these variables need to be set to 4.32-4.34. If the intermediate membership threshold of these variables is set to 4.32 , it will lead to a calibrated data distribution. Therefore, the intermediate membership threshold of these variables was set to 4.34 . By setting the three thresholds, fsQCA converts the scores of these variables into fuzzy scores between zero and 1 . 
TABle 2: Descriptive statistics.

\begin{tabular}{|c|c|c|c|}
\hline Characteristic & & Frequency & Percentage \\
\hline \multirow{2}{*}{ Position } & CIO/CTO/IT department manager & 67 & 54.47 \\
\hline & Other managers of the IT department & 56 & 45.53 \\
\hline \multirow{13}{*}{ Industry } & Mining industry & 21 & 17.07 \\
\hline & Electricity, heat, gas, and water production and supply & 5 & 4.07 \\
\hline & Real estate & 1 & 0.81 \\
\hline & Construction business & 1 & 0.81 \\
\hline & Transportation, storage, and postal industry & 7 & 5.69 \\
\hline & Financial industry & 7 & 5.69 \\
\hline & Wholesale and retail & 11 & 8.94 \\
\hline & Water conservancy, environment, and public facilities management industry & 2 & 1.63 \\
\hline & Culture, sports, and entertainment industry & 2 & 1.63 \\
\hline & Information transmission, software and information technology service industry & 59 & 47.97 \\
\hline & Manufacturing & 5 & 4.07 \\
\hline & Leasing and business services & 1 & 0.81 \\
\hline & Scientific research and technical service industry & 1 & 0.81 \\
\hline \multirow{4}{*}{ Enterprise size } & $21-50$ & 10 & 8.13 \\
\hline & $51-100$ & 18 & 14.63 \\
\hline & $100-200$ & 35 & 28.46 \\
\hline & More than 200 & 60 & 48.78 \\
\hline \multirow{4}{*}{ Enterprise age } & $2-5$ & 21 & 17.07 \\
\hline & $6-10$ & 47 & 38.21 \\
\hline & $11-20$ & 43 & 34.96 \\
\hline & More than 20 & 12 & 9.76 \\
\hline \multirow{9}{*}{ Annual turnover (RMB) } & $1010000-5000000$ & 7 & 5.69 \\
\hline & $5010000-10000000$ & 14 & 11.38 \\
\hline & $10010000-50000000$ & 34 & 27.64 \\
\hline & $50010000-100000000$ & 29 & 23.58 \\
\hline & $100000000-300000000$ & 15 & 12.20 \\
\hline & $300000000-500000000$ & 11 & 8.94 \\
\hline & $500000000-1000000000$ & 4 & 3.25 \\
\hline & More than 1000000000 & 4 & 3.25 \\
\hline & Inconvenient to disclose & 5 & 4.07 \\
\hline \multirow{4}{*}{ Number of IT staff } & Less than 5 & 9 & 7.32 \\
\hline & $5-10$ & 33 & 26.83 \\
\hline & $11-20$ & 30 & 24.39 \\
\hline & More than 20 & 51 & 41.46 \\
\hline \multirow{6}{*}{ IT annual investment budget } & Less than 1000000 & 19 & 15.45 \\
\hline & $1000000-10000000$ & 75 & 60.98 \\
\hline & $10000000-100000000$ & 16 & 13.00 \\
\hline & More than 100000000 & 5 & 4.07 \\
\hline & Inconvenient to disclose & 7 & 5.69 \\
\hline & Not clear & 1 & 0.81 \\
\hline
\end{tabular}

After the data calibration, fsQCA 3.0 was used to analyze the truth table. After deleting the cases with frequencies of zero and 1 , and a consistency of less than $0.8,76 \%$ of the samples were retained, and a standardized analysis was used to identify the antecedent configuration of enterprises adopting the cloud services. The QCA analysis results report three solutions: complex, intermediate, and parsimonious solutions. The conditions that appear in both the parsimonious and intermediate solutions are the core conditions, whereas the conditions that only exist in the intermediate solution are peripheral. In addition, variables with a consistency of greater than 0.9 are necessary conditions, and must be the core conditions. The core condition has a strong causal relationship with the outcome, and the peripheral condition has a weaker relationship.

\section{Results and Discussion}

5.1. Analysis of Necessity. We tested the necessary conditions for the presence of cloud service adoption. For cloud service adoption, the consistency values range between 0.41 and 0.87 for both the presence and negation of the casual conditions. 
No single condition on its own leads to cloud service adoption because none of the casual conditions exceeds a value of 0.9 . Thus, we proceed with a fuzzy-set analysis to identify sufficient combinations of casual conditions that explain the cloud service adoption. The results of the analysis of the necessary conditions are presented in Table 3.

\subsection{Analysis of Sufficiency. The findings from fsQCA on the} configurations for cloud service adoption by SMEs are presented in Table 4.

The solutions were grouped according to the core conditions. Every combination in the solution can explain the same outcome at a specific amount. Consistency values are presented in Table 4 for each solution as well, with all values being higher than the recommended threshold $(>0.75)$. Consistency shows the degree to which the relationship has been approximated, and coverage evaluates the empirical relevance of a consistent subset. The overall consistency was similar to the correlation showing the robustness of the solution. The overall solution coverage indicates the extent to which a high satisfaction may be determined from the existing configurations and is comparable to the R-square value reported in traditional regression analyses. The overall solution coverage of 0.74 indicates that the six solutions explain $74 \%$ of the outcome.

Furthermore, fsQCA computes the empirical relevance for each solution by calculating the raw and unique coverage. The raw coverage describes the amount of the outcome explained by a certain alternative solution, whereas the unique coverage describes the amount of the outcome that is exclusively explained by an alternative solution. The coverage of each configuration was greater than zero. Thus, all configurations are empirically relevant.

For cloud service adoption by SMEs, solutions 1-6 present combinations for which the examined factors may be present or absent, depending on how they combine with each other.

5.2.1. Solution 1. In configurations $1 \mathrm{a}-1 \mathrm{c}$, government support is the core condition and is present, which means that enterprises with political, economic, and social resources provided by the government are more inclined to adopt cloud services. Moreover, in configurations 1a-1c, top management support, IT capability, and competitive pressure are peripheral conditions and are absent, indicating that government support is particularly important for enterprises with unclear support of the top management, incomplete IT technology, and no significant pressure from competitors in the same industry to adopt cloud services. In addition, the relative advantage and provider capability in configuration la are peripheral conditions and absent, whereas perceived security risk is an irrelevant condition. In configuration $1 \mathrm{~b}$, perceived security risk is a core condition and is present, and the provider capability is a peripheral condition and absent, and a relative advantage is an irrelevant condition. For configuration 1c, perceived security risk is a peripheral condition and is present, and a relative advantage is a peripheral condition and is absent, whereas the provider
TABLE 3: Analysis of necessary conditions.

\begin{tabular}{lcc}
\hline & Consistency & Coverage \\
\hline fzRA & 0.827 & 0.765 \\
$\sim$ fzRA & 0.481 & 0.688 \\
fzPSR & 0.603 & 0.749 \\
$\sim$ fzPSR & 0.775 & 0.795 \\
fzTMS & 0.846 & 0.824 \\
$\sim$ fzTMS & 0.535 & 0.709 \\
fzIT & 0.865 & 0.851 \\
$\sim$ fzIT & 0.524 & 0.686 \\
fzCP & 0.810 & 0.834 \\
$\sim$ fzCP & 0.540 & 0.666 \\
fzGS & 0.786 & 0.792 \\
$\sim$ fzGS & 0.556 & 0.704 \\
fzPA & 0.875 & 0.750 \\
$\sim$ fzPA & 0.412 & 0.671 \\
\hline
\end{tabular}

capability is an irrelevant condition. It can be seen from configurations $1 \mathrm{a}-1 \mathrm{c}$ that government support has a significant influence on the decision of an enterprise to adopt cloud services. For enterprises supported by the government, even if other conditions affecting the adoption of cloud services are incomplete, it is easier for them to incorporate cloud services into the decision of the enterprise operation and management. These solutions explain the cloud service adoption of SMEs at rates of $23.5 \%, 23.7 \%$, and $27.2 \%$.

5.2.2. Solution 2. In configurations $2 \mathrm{a}$ and $2 \mathrm{~b}$, relative advantage, IT capability, and provider capability are the core conditions. This means that the feeling regarding a cloud service can bring about a relative advantage, having a complete IT capability, and for cloud providers with high technology and management service capabilities, enterprises are more inclined to adopt their services. Cloud services, enterprises, and cloud providers, as the three central bodies, all play a vital role in the process of enterprise adoption of cloud services. Only when the three complement and cooperate with each other can they further encourage enterprises to adopt cloud services. Furthermore, in configurations $2 \mathrm{a}$ and $2 \mathrm{~b}$, government support is the peripheral condition and is absent, indicating that as long as the relative advantages of the cloud services are sufficient, the IT capability of the enterprise is sufficient, and the cloud provider's capability is sufficient to support the provisioning of high-quality cloud services. Even if there is no government financial support, enterprises will also adopt cloud services because of the high performance, versatility, and high efficiency of the cloud platform. In addition, in configuration 2a, top management support is a peripheral condition and is present, and the perceived security risk is a peripheral condition and is absent. In addition, the competitive pressure is an irrelevant condition; in configuration $2 \mathrm{~b}$, perceived security risk is a peripheral condition and is present, and top management support and competitive pressure are peripheral conditions and are absent. It can be seen from configurations $2 \mathrm{a}$ and $2 \mathrm{~b}$ that the relative advantages of cloud services and cloud service provider capabilities significantly impact the adoption of cloud services 
TABLE 4: FsQCA analysis results.

\begin{tabular}{|c|c|c|c|c|c|c|c|c|c|}
\hline & \multicolumn{9}{|c|}{ Cloud service adoption by SMEs } \\
\hline & \multicolumn{3}{|c|}{1} & \multicolumn{2}{|c|}{2} & \multirow{2}{*}{3} & \multirow{2}{*}{4} & \multirow{2}{*}{5} & \multirow{2}{*}{6} \\
\hline & $1 \mathrm{a}$ & $1 \mathrm{~b}$ & 1c & $2 \mathrm{a}$ & $2 b$ & & & & \\
\hline RA & $\otimes$ & & $\otimes$ & $\bullet$ & $\bullet$ & $\bullet$ & $\otimes$ & $\bullet$ & $\otimes$ \\
\hline PSR & & $\bullet$ & ○ & $\otimes$ & $\bullet$ & & $\otimes$ & - & $\bullet$ \\
\hline TMS & $\otimes$ & $\otimes$ & $\otimes$ & $\bullet$ & $\otimes$ & $\bullet$ & $\otimes$ & $\bullet$ & $\bullet$ \\
\hline IT & $\otimes$ & $\otimes$ & $\otimes$ & $\bullet$ & $\bullet$ & $\bullet$ & $\otimes$ & $\bullet$ & $\bullet$ \\
\hline $\mathrm{CP}$ & $\otimes$ & $\otimes$ & $\otimes$ & & $\otimes$ & - & $\otimes$ & $\otimes$ & $\otimes$ \\
\hline GS & $\bullet$ & $\bullet$ & $\bullet$ & $\otimes$ & $\otimes$ & $\bullet$ & $\otimes$ & $\otimes$ & $\bullet$ \\
\hline PA & $\otimes$ & $\otimes$ & & $\bullet$ & $\bullet$ & $\bullet$ & $\bullet$ & $\otimes$ & $\otimes$ \\
\hline Consistency & 0.786 & 0.833 & 0.861 & 0.946 & 0.952 & 0.982 & 0.883 & 0.932 & 0.945 \\
\hline Raw coverage & 0.235 & 0.237 & 0.272 & 0.418 & 0.269 & 0.558 & 0.254 & 0.210 & 0.208 \\
\hline Unique coverage & 0.004 & 0.004 & 0.008 & 0.033 & 0.013 & 0.185 & 0.008 & 0.013 & 0.005 \\
\hline Solution coverage & & & & & 0.740 & & & & \\
\hline Solution consistency & & & & & 0.842 & & & & \\
\hline
\end{tabular}

Black circles ("๑") indicate the presence of a condition, and circles with a cross-out (" $\otimes$ ") indicate the absence of a condition. Furthermore, large circles indicate core conditions, and small circles indicate peripheral conditions. Blank spaces indicate a "do not care" situation in which the causal condition may be either present or absent.

by enterprises. Therefore, cloud service providers should strive to improve their service capabilities and make enterprises deeply feel the relative advantages of cloud services, such that more enterprises will willing adopt cloud services. These solutions explain the cloud service adoption of SMEs at rates of $41.8 \%$ and $26.9 \%$, respectively.

5.2.3. Solution 3. In configuration 3 , the relative advantage, IT capability, government support, and provider capability are core conditions and are present, top management support and competitive pressure are peripheral conditions and are present, and perceived security risk is an irrelevant condition. This configuration shows that for enterprises with relatively complete IT capabilities, the government support, higher cloud service provider capabilities, and perceived advantages of cloud services will make enterprises more willing to adopt cloud services. In the discussion of configuration 1, it can be seen that government support can promote enterprises to adopt cloud services; in the discussion of configuration 2, it can be seen that the relative advantages of cloud services, the IT capabilities of enterprises, and the capabilities of cloud providers can jointly promote the adoption of cloud services by enterprises. Therefore, if an enterprise with relatively complete IT capability chooses a cloud service provider with strong technical service capabilities and management service capabilities and feels the relative advantages of cloud services, it will undoubtedly make a decision to adopt cloud services with the strong support of the government. This configuration further illustrates the vital role that the government plays in promoting the adoption of cloud services by an enterprise. In addition, top management support and competitive pressure in configuration 3 are peripheral conditions and are present, which means that full understanding and trust of cloud services from top management, the resources allocated to cloud services, and the pressure brought by industry competitors will promote the adoption of cloud services by enterprises to a certain extent. This solution explains cloud service adoption of SMEs at a rate of $55.8 \%$.
5.2.4. Solution 4. In configuration 4, provider capability is the core condition and is present, and the relative advantage, perceived security risk, top management support, IT capability, competitive pressure, and government support are peripheral conditions and are absent. This indicates that as long as the technical services and management services capability of the cloud service provider are mature and sufficiently trustworthy, even if there are no other conditions that promote the adoption of cloud services by an enterprise, the enterprise will also be willing to entrust the cloud service provider with the implementation of work related to cloud services, deploy websites and systems to the cloud service platforms, and allow cloud service providers to provide service deployment, service choreography, cloud service management, and security and privacy protection for the enterprise. In addition, perceived security risk is the peripheral condition and is absent, indicating that enterprises do not perceive that cloud services will bring risks to the organizational performance under the condition of strong cloud service providers, which will further promote enterprises to adopt cloud services. This solution explains cloud service adoption of SMEs at a rate of $25.4 \%$.

5.2.5. Solution 5. In configuration 5 , relative advantage and IT capability are core conditions and are present; perceived security risk and top management support are peripheral conditions and are present; and competitive pressure, government support, and provider capability are peripheral conditions and are absent, indicating that for enterprises with complete IT capabilities, if they feel that the cloud service will bring relative advantages for the enterprise, they will tend to adopt such services. Top management support is a peripheral condition and is present, indicating that enterprises with top management who support cloud service adoption decisions will be more willing to adopt cloud services. Compared with configuration $2 \mathrm{~b}$, it can be seen that even if the enterprise is not overly confident in the technical service ability and management serviceability of the cloud 
service provider, it is possible to adopt cloud services to take advantage of its relative advantages to improve their business performance and operating efficiency. This is because the top management can feel that the cloud service will bring advantages to the enterprises and be willing to actively participate in the development of the cloud services strategy. Other peripheral conditions indicate that, regardless of whether the enterprise feels competitive pressure, receives government support, perceives the risks that cloud services will bring, or has a capable cloud service provider, as long as the cloud service brings obvious relative advantages to the enterprise, which has relatively strong IT capability, it will adopt the services. This solution explains the cloud service adoption of SMEs at a rate of $21 \%$.

5.2.6. Solution 6. In configuration 6, IT capability and government support are core conditions and are present, and perceived security risk and top management support are peripheral conditions and are also present. Relative advantage, competitive pressure, and provider capability are peripheral conditions and are absent, indicating that the IT capability of the enterprise is relatively complete. The enterprise is supported by the political, economic, and social resources of the government for adopting cloud services, and will adopt the cloud services. Top management support is a peripheral condition and is present, indicating that the top management is willing to allocate resources to implement cloud services and encourage employees to use cloud services, which will further promote the adoption of cloud services by an enterprise. Other peripheral conditions indicate whether the enterprise perceives the relative advantages or security risks that the cloud services will bring, whether it feels competitive pressure, and whether the capabilities of the cloud service providers are complete; in addition, as long as the enterprise has high IT capabilities and is supported by the government, it will be confident to adopt cloud services owing to the "cloud service coupons" (financial cloud service subsidies) issued by the government. This solution explains the cloud service adoption of SMEs at a rate of $20.8 \%$.

\section{Conclusion}

To survive in a competitive environment, SMEs have had to adapt to the digital environment and adjust to customer needs globally, particularly in a post-COVID-19 world. The advantages of cloud computing (e.g., flexibility, scalability, and low entry cost) provide opportunities for SMEs with a restricted budget and limited resources. Small businesses can improve their operations and productivity enormously by moving to the cloud. Doing so will increase their revenue, thereby setting them ahead of the competition. To accelerate the digital transformation of SMEs and promote the development of the cloud computing industry, it is of great significance to explore ways to encourage SMEs to adopt cloud computing and make relevant and targeted measures.

SMEs need to consider multiple factors when incorporating cloud service adoption into their business management decisions. We argue that different combinations (or configurations) of multiple antecedents can explain SMEs' adoption of cloud services. To identify such combinations, we build on complexity and configuration theories, propose a conceptual model that includes seven antecedents (i.e., relative advantage, perceived security risk, top management support, IT competence, competitive pressure, government support, provider capability), and use fsQCA (asymmetric) to identify nine configurations for the adoption of cloud service.

The findings show that government support is present in three out of six solutions and always as a core factor, suggesting that it plays a critical role in driving SMEs to adopt cloud services. The Chinese government, particularly local governments, can significantly influence the business decisions of an enterprise. The government usually formulates policies conducive to a particular business in specific regions and industries, or issues policies for enterprises of a specific size and ownership type. If necessary, the government may even provide financial support to enterprises to encourage them to comply with government guidelines. Cai et al. [76] proposed that government support can promote enterprises to integrate the supply chain information, reflecting the influence of government support on enterprise decisionmaking.

Our findings also show that provider capability is present in three out of six solutions and always as a core factor, indicating that the strong technical service capabilities and management service capabilities of a cloud service provider can encourage an SME to adopt its cloud services. Indeed, Liang et al. [41] proposed that the capability of a cloud provider can affect the cloud provider support and thus the adoption of an e-government cloud, but it has not proven to have a significant promoting effect. Fu et al. [85] pointed out that the ability of a cloud service provider will affect the adoption of cloud computing by an enterprise, although research results have shown that this is not an extremely important factor. However, in this study, provider capability is present as the core condition in the three configurations, indicating that this factor has an essential effect on the adoption of cloud services of an SME.

In addition, our findings show that a relative advantage is present in three out of six solutions and is always a core factor. Many studies prove that the relative advantage can significantly promote the adoption of cloud services by an enterprise $[23,28]$. The results of this study confirm this conclusion. Therefore, cloud service providers should continuously strive to improve the quality of their services, and thus enterprises can further feel the relative advantages of cloud services, such as flexibility, scalability, low entry, and computing cost.

Finally, our findings show that IT competence is present in four out of six solutions and is always as a core factor, suggesting that it plays a critical role in driving SMEs to adopt cloud services. Oliveira et al. [23] and Martins et al. [36] proposed and proved that technology competence could significantly positively influence SaaS adoption by enterprises. The results of this study further indicate that the IT capabilities of an enterprise play an essential role in 
promoting the adoption of cloud services. Enterprises should strive to improve their own IT capabilities, increase investment in IT hardware and software, and improve the quality of the IT staff to prepare for the adoption of cloud services at any time.

6.1. Theoretical Implications. In the context of the country using cloud computing as a development strategy, we need to increase our understanding of SME adoption and investigate internal factors and how they lead to more adoptions. Our findings identify multiple combinations that explain cloud service adoption in SMEs and offer two main contributions.

This study systematically sorted the latest research on the factors that affect cloud service adoption through a literature review. After such sorting, it was found that the existing literature mostly uses the TOE framework, DOI theory, and technology acceptance model as the theoretical basis when proposing research models, and mostly uses partial least squares (PLS), regression analysis, and structural equation modeling (SEM) as research methods. In recent years, after some theoretical frameworks have become more mature, and more research methods have gradually emerged, no research has specifically reviewed the latest studies on the factors affecting cloud service adoption. The combined effort in the study can help scholars find the research gap in this type of research, explore more factors that affect the adoption of cloud services, establish a more scientific and systematic research model based on existing research, and conduct innovative research in this field.

Another theoretical implication of this study lies in the innovative use of new research methods. We use fsQCA in the research field of factors that influence enterprises to adopt cloud services. Existing studies have mostly used PLS, regression analysis, and SEM to explore the factors affecting the adoption of cloud services of an enterprise. These methods assume that the relations between variables are symmetric [ 86,87$]$, but the relations can also be asymmetric in real life. These methods are also dedicated to studying the independent effects of independent variables on dependent variables, although the relationship between independent variables in real life is often interdependent, and they will work together to lead to specific results. This situation occurs when SMEs make cloud service adoption decisions. They often need to consider multiple factors to decide whether to adopt a cloud service, and these factors often exist simultaneously and affect the decision-making. In addition, the research of relevant scholars also shows that there is a causal asymmetry in an enterprise adoption of cloud services; for example, Tashkandi and Al-Jabri [28] pointed out that the relative advantage of cloud services has a significant positive impact on cloud service adoption, whereas Low et al. [5] verified a significant negative impact. Building on complexity and configuration theories, fsQCA can capture the causal asymmetry between many factors and the adoption of cloud services by an enterprise, resulting in new research models and theories. Based on the TOE framework, this study uses fsQCA to study the joint effects of the relative advantage, perceived security risk, top management support, IT capability, competitive pressure, government support, and provider capability on the adoption of cloud services, and identifies nine paths that lead an enterprise to adopt cloud services. This study innovatively uses the fsQCA to expand the conclusions of existing research, and at the same time, will provide researchers with a new way to think and operate tools to continuously enrich the research in this field.

In addition, this research enriches the application of QCA in the field of management. In the management area, existing studies have used the QCA method in human resource management, innovation management, international business, entrepreneurial management, knowledge management, corporate governance, social responsibility, stakeholder management, strategic management, organizational design, project management, and marketing management; however, no scholars have used the QCA method in the field of enterprise adoption of cloud services. This study uses fsQCA to explore the nine paths that will lead enterprises to adopt cloud services, which opens up new areas for applying the QCA method, further enhancing the understanding of this method for management scholars, and promoting the development of management theory.

6.2. Practical Implications. The results of this study have important guiding significance and enlightenment for enterprise management practitioners. With the in-depth development of cloud computing technology, cloud service providers have landed and officially commercialized both at home and abroad, and the term "cloud" has become the norm for corporate development. Particularly since the outbreak of COVID-19 in early 2020, the Ministry of Industry and Information Technology of China has required the use of cloud computing and other technologies to help enterprises resume work and production. Cloud services can drive process and business innovations and become a new profit growth point for enterprises. However, in the face of the state promotion of enterprises to adopt cloud services and the benefits that cloud services can bring to them, some enterprises have still refused to adopt cloud services owing to a weak awareness and the security issues of cloud services. This study identified nine paths that lead enterprises to adopt cloud services. The results will provide relevant practical guidance for governments, cloud service providers, and enterprises to promote the adoption of cloud services, thereby enhancing the leading position and firm competitiveness of the cloud computing industry in China.

First, the research results show that government support is present as a core factor in three out of six solutions, indicating that it plays a vital positive role in the adoption of cloud services by enterprises. Therefore, to promote the use of cloud computing to accelerate the digitalization, networking, and intelligent transformation of enterprises, and to promote the development of the cloud computing industry, governments at all levels should correctly and rationally understand the development path of cloud services and scientifically promote the adoption of cloud services by 
enterprises. Thus, we propose two specific suggestions for governments.

On the one hand, the government should strengthen the infrastructure of cloud services, formulate more preferential policies, and increase support for enterprises to adopt cloud services. At present, to promote the coordinated development of industries and maximize the creation of corporate value, China has successively formulated and promulgated the "Industrial Internet Plat-form Construction and Promotion Guidelines," "Promoting Enterprise Cloud Implementation Guidelines (2018-2020)," and other policy documents to help SMEs adopt cloud services. In the future, the government should strictly implement the content of the document and put forward more innovative opinions. Meanwhile, the government can set up a team of experts to provide policy interpretation services and legal support to enterprises.

On the other hand, the government should give priority support to enterprises that lack complete IT capabilities and top management support for cloud service adoption, providing them with relevant policy guidance and technical support. This is due to IT capability, and top management support is a peripheral condition and is absent in configuration 1. An expert team can also be organized to provide training to the IT employees of such enterprises, such as educating them on how to comprehend and use cloud services, or how to choose cloud service providers. Furthermore, cloud service "coupons" should be issued to these enterprises to fully promote the application of cloud services and give full-play to the positive role of such services in enterprise operation and management.

Second, provider capability is present in three out of six solutions and is always as a core factor, suggesting that it is an essential subject in the process of enterprises adopting cloud services. Therefore, cloud service providers can not only help enterprises improve their IT architecture and achieve business growth but also reduce the pressure on enterprise operation and maintenance through high-quality services. To attract more SMEs to adopt cloud services, cloud service providers should continuously improve their technical service capabilities and management service capabilities and achieve higher technological advancement and service standardization, thereby improving the stability, security, and availability of the cloud platform infrastructure. These measures can further enhance their relative advantages. They should enhance their own ability to protect user data security by building a data security capability scale, full life cycle security capability requirements, and data security capability dimensions; thus, enterprises can safely outsource their work related to cloud services to cloud service providers. At the same time, the providers should provide good after-sales services to enterprises that have already adopted cloud services to increase their satisfaction with cloud services and form a word-of-mouth effect.

Third, because IT capability is a core condition and is present in four out of six solutions, enterprises should focus on building their own IT capabilities, increase investment in IT hardware and software, deploy a good IT environment and essential software and hardware facilities, attach importance to the development of IT departments, and form excellent IT teams to support enterprises in applying cloud services better, thereby promoting the construction of enterprise informatization. At the same time, top management of the enterprises should promote and popularize cloud services, actively participate in the formulation of the cloud service vision and strategy, improve the ability of employees to accept new technologies, and focus on the promotion of IT department managers. This will provide a solid foundation for enterprises to deploy cloud services, accelerate innovation, and reduce costs to ensure that enterprises remain competitive in the wave of industry adoption of cloud services.

6.3. Limitations and Directions for Future Work. As a limitation of this study, the number of factors considered was relatively small. Only seven factors were studied on the joint effect of enterprise adoption of cloud services. In addition, the research object of this study was only SMEs in China. Because the sample selection is restricted by region and scale, the universality of the nine configurations that can enable enterprises to adopt cloud services obtained in this study needs to be further explored and analyzed. Based on this research, in the future, we will use the QCA method to study other factors that lead enterprises to adopt cloud services and expand the scope of research objects to enterprises in Asia, further increasing the breadth and depth of this research.

\section{Data Availability}

The data used to support the findings of this study are available from the corresponding author upon request.

\section{Conflicts of Interest}

The authors declare that there are no conflicts of interest regarding the publication of this paper.

\section{Acknowledgments}

This research was funded by the National Social Science Fund of China (17BGL198 and 20FGLB070).

\section{References}

[1] C. Rodríguez-Monroy, C. Arias, and Y. Núñez Guerrero, "The new cloud computing paradigm: the way to IT seen as a utility," Latin American and Caribbean Journal of Engineering Education, vol. 6, pp. 24-31, 2012.

[2] M. Armbrust, A. Fox, R. Griffith et al., "A view of cloud computing," Communications of the ACM, vol. 53, no. 4, pp. 50-58, 2010.

[3] R. Buyya, C. S. Yeo, S. Venugopal, J. Broberg, and I. Brandic, "Cloud computing and emerging IT platforms: vision, hype, and reality for delivering computing as the 5th utility," Future Generation Computer Systems, vol. 25, no. 6, pp. 599-616, 2009. 
[4] G. Garrison, S. Kim, and R. L. Wakefield, "Success factors for deploying cloud computing," Communications of the ACM, vol. 55, no. 9, pp. 62-68, 2012.

[5] C. Low, Y. Chen, and M. Wu, "Understanding the determinants of cloud computing adoption," Industrial Management \& Data Systems, vol. 111, no. 7, pp. 1006-1023, 2011.

[6] N. Sultan, "Cloud computing for education: a new dawn?" International Journal of Information Management, vol. 30, no. 2, pp. 109-116, 2010.

[7] L. I. Min, D. Zhao, and Y. Yu, "TOE drivers for cloud transformation: direct or trust-mediated?" Asia Pacific Journal of Marketing and Logistics, vol. 27, no. 2, pp. 226-248, 2015.

[8] Ali and Al-Khouri, "Digital identity: transforming GCC economies," Innovation, vol. 16, no. 2, 2015.

[9] A. Prasad and P. Green, "Governing cloud computing services: reconsideration of IT governance structures," International Journal of Accounting Information Systems, vol. 19, pp. 45-58, 2015.

[10] M. Sharma, R. Gupta, and P. Acharya, "Prioritizing the critical factors of cloud computing adoption using multi-criteria decision-making techniques," Global Business Review, vol. 21, no. 1, 2017.

[11] S. Trigueros-Preciado, D. Pérez-González, and P. SolanaGonzález, "Cloud computing in industrial SMEs: identification of the barriers to its adoption and effects of its application," Electronic Markets, vol. 23, no. 2, pp. 105-114, 2013.

[12] V. M. Dincă, A. M. Dima, and Z. Rozsa, "Determinants of cloud computing adoption by Romanian smes in the digital economy," Journal of Business Economics and Management, vol. 20, no. 4, pp. 798-820, 2019.

[13] C. C. Ragin, "The comparative method: moving beyond qualitative and quantitative strategies," Social Forces, vol. 67, no. 3, 1987.

[14] P. M. Mell and T. Grance, The NIST Definition of Cloud Computing, National Institute of Standards \& Technology, Gaithersburg, MA, USA, 2011.

[15] A. Ezgi and M. "Sona, "Analyzing factors affecting the adoption of cloud computing: a case of Turkey," KSII Transactions on Internet and Information Systems, vol. 10, no. $1,2016$.

[16] M. Armbrust, Above the Clouds: A Berkeley View of Cloud Computing, University of California, Berkeley, CA, USA, 2009.

[17] S. Saya, L. G. Pee, and A. Kankanhalli, "The impact of institutional influences on perceived technological characteristics and real options in cloud computing adoption," in Proceedings of the International Conference on Information Systems, Saint Louis, MI, USA, December 2010.

[18] W.-W. Wu, "Developing an explorative model for SaaS adoption," Expert Systems with Applications, vol. 38, no. 12, pp. 15057-15064, 2011.

[19] N. Alkhater, R. Walters, and G. Wills, "An investigation of factors influencing an organisation's intention to adopt cloud computing," in Proceedings of the International Conference on Information Society (i-Society 2014), pp. 337-338, London, UK, November 2014.

[20] T. S. Behrend, E. N. Wiebe, J. E. London, and E. C. Johnson, "Cloud computing adoption and usage in community colleges," Behaviour \& Information Technology, vol. 30, no. 2, pp. 231-240, 2011.

[21] D. Dang-Pham and M. Nkhoma, "Contributing factors of cloud computing adoption: a technology-organisation-environment framework approach," International Journal of Information Systems and Engineering, vol. 1, pp. 38-49, 2013.

[22] P. Gupta, A. Seetharaman, and J. R. Raj, "The usage and adoption of cloud computing by small and medium businesses," International Journal of Information Management, vol. 33, no. 5, pp. 861-874, 2013.

[23] T. Oliveira, M. Thomas, and M. Espadanal, "Assessing the determinants of cloud computing adoption: an analysis of the manufacturing and services sectors," Information \& Management, vol. 51, no. 5, pp. 497-510, 2014.

[24] J.-W. Lian, D. C. Yen, and Y.-T. Wang, "An exploratory study to understand the critical factors affecting the decision to adopt cloud computing in Taiwan hospital," International Journal of Information Management, vol. 34, no. 1, pp. 28-36, 2014.

[25] P.-F. Hsu, S. Ray, and Y.-Y. Li-Hsieh, "Examining cloud computing adoption intention, pricing mechanism, and deployment model," International Journal of Information Management, vol. 34, no. 4, pp. 474-488, 2014.

[26] N. Alkhater, G. Wills, and R. Walters, "Factors influencing an organisation's intention to adopt cloud computing in Saudi Arabia," in Proceedings of the 2014 IEEE 6th International Conference on Cloud Computing Technology and Science, Singapore, December 2015.

[27] Z. Yang, J. Sun, Y. Zhang, and Y. Wang, "Understanding SaaS adoption from the perspective of organizational users: a tripod readiness model," Computers in Human Behavior, vol. 45, pp. 254-264, 2015.

[28] A. N. Tashkandi and I. M. Al-Jabri, "Cloud computing adoption by higher education institutions in Saudi Arabia: an exploratory study," Cluster Computing, vol. 18, no. 4, pp. 1527-1537, 2015.

[29] F. Safari, N. Safari, and A. Hasanzadeh, "The adoption of software-as-a-service (SaaS): ranking the determinants," Journal of Enterprise Information Management, vol. 28, no. 3, pp. 400-422, 2015.

[30] Y. C. Lee, "Why do people adopt cloud services? gender differences," Social Ence Information, vol. 55, no. 1, 2016.

[31] C.-L. Hsu and J. C.-C. Lin, "Factors affecting the adoption of cloud services in enterprises," Information Systems and E-Business Management, vol. 14, no. 4, pp. 791-822, 2016.

[32] N. Aharony, "An exploratory study on factors affecting the adoption of cloud computing by information professionals," The Electronic Library: The International Journal for Minicomputer, Microcomputer, and Software Applications in Libraries, vol. 33, no. 2, pp. 308-323, 2015.

[33] J. Wu, F. Ding, M. Xu, Z. Mo, and A. Jin, "Investigating the determinants of decision-making on adoption of public cloud computing in E-government," Journal of Global Information Management, vol. 24, no. 3, pp. 71-89, 2016.

[34] T.-Y. Shih and C.-W. Lin, "Cloud service adoption by firms in Taiwan," Information Development, vol. 33, no. 5, pp. 495-511, 2016.

[35] H. M. Sabi, F.-M. E. Uzoka, K. Langmia, and F. N. Njeh, "Conceptualizing a model for adoption of cloud computing in education," International Journal of Information Management, vol. 36, no. 2, pp. 183-191, 2016.

[36] R. Martins, T. Oliveira, and M. A. Thomas, "An empirical analysis to assess the determinants of SaaS diffusion in firms," Computers in Human Behavior, vol. 62, pp. 19-33, 2016.

[37] S. Tomas, M. Thomas, and T. Oliveira, "Evaluating the impact of virtualization characteristics on SaaS adoption," Enterprise Information Systems, vol. 12, no. 1-5, pp. 259-278, 2018. 
[38] H. M. Sabi, F. M. E. Uzoka, K. Langmia, F. N. Njeh, and C. K. Tsuma, "A cross-country model of contextual factors impacting cloud computing adoption at universities in subSaharan Africa," Information Systems Frontiers, vol. 20, pp. 1381-1404, 2017.

[39] P. R. Palos-Sanchez, F. J. Arenas-Marquez, and M. AguayoCamacho, "Cloud computing (SaaS) adoption as a strategic technology: results of an empirical study," Mobile Information Systems, vol. 2017, p. 20, 2017.

[40] J. M. Maqueira-Marín, S. Bruque-Cámara, and B. MinguelaRata, "Environment determinants in business adoption of cloud computing," Industrial Management \& Data Systems, vol. 117, pp. 1-19, 1980.

[41] Y. Liang, G. Qi, K. Wei, and J. Chen, "Exploring the determinant and influence mechanism of e-Government cloud adoption in government agencies in China," Government Information Quarterly, vol. 34, no. 3, pp. 481-495, 2017.

[42] R. D. Raut, P. Pragati, B. B. Gardas, and J. M. Kumar, "Analyzing the factors influencing cloud computing adoption using three stage hybrid SEM-ANN-ISM (SEANIS) approach," Technological Forecasting and Social Change, vol. 134, 2018.

[43] T. Oliveira, R. Martins, S. Sarker, M. Thomas, and A. Popovič, "Understanding SaaS adoption: the moderating impact of the environment context," International Journal of Information Management, vol. 49, pp. 1-12, 2019.

[44] R. Drazin, G. Tornatzky, and M. Fleischer, "The processes of technological innovation," The Journal of Technology Transfer, vol. 16, no. 1, pp. 45-46, 1991.

[45] B. Yeo and D. Grant, "Predicting service industry performance using decision tree analysis," International Journal of Information Management, vol. 38, no. 1, pp. 288-300, 2018.

[46] D. K. Maduku, M. Mpinganjira, and H. Duh, "Understanding mobile marketing adoption intention by South African SMEs: a multi-perspective framework," International Journal of Information Management, vol. 36, no. 5, pp. 711-723, 2016.

[47] P. K. Senyo, J. Effah, and E. Addae, "Preliminary insight into cloud computing adoption in a developing country," Journal of Enterprise Information Management, vol. 29, no. 4, pp. 505-524, 2016.

[48] T. Oliveira and M. F. Martins, "Literature review of information technology adoption models at firm level," Electronic Journal of Information Systems Evaluation, vol. 1, no. 2, pp. 312-323, 2011.

[49] M. J. Pan and W. Y. Jang, "Determinants of the adoption of enterprise resource planning within the technology-organizationenvironment framework: Taiwan's communications industry," Data Processor for Better Business Education, vol. 48, no. 3, pp. 94-102, 2008.

[50] S. C. Srivastava and S. H. T. Thompson, "E-government, E-business and national economic performance," Сommunications of the Association for Information Systems, vol. 26, no. 1, 2010.

[51] Y.-M. Wang, Y.-S. Wang, and Y.-F. Yang, "Understanding the determinants of RFID adoption in the manufacturing industry," Technological Forecasting and Social Change, vol. 77, no. 5, pp. 803-815, 2010.

[52] A. Soares-Aguiar and A. Palma-Dos-Reis, "Why do firms adopt E-procurement systems? using logistic regression to empirically test a conceptual model," IEEE Transactions on Engineering Management, vol. 55, no. 1, pp. 120-133, 2008.

[53] V. Venkatesh and H. Bala, "Adoption and impacts of interorganizational business process standards: role of partnering synergy," Information System Researchs, vol. 23, no. 4, pp. 1131-1157, 2012.

[54] T. E. Yoon and J. F. George, "Why aren't organizations adopting virtual worlds?" Computers in Human Behavior, vol. 29, no. 3, pp. 772-790, 2013.

[55] J. DiMaggio, P. Paul, and W. Walter, "The iron cage revisited: institutional isomorphism and collective rationality in organizational fields," American Sociological Review, vol. 48, no. 2, pp. $147-160,1983$.

[56] F. P. Tajudeen, N. I. Jaafar, and S. Ainin, "Understanding the impact of social media usage among organizations," Information \& Management, vol. 55, no. 3, pp. 308-321, 2018.

[57] C.-T. Liu, Y. M. Guo, and C.-H. Lee, "The effects of relationship quality and switching barriers on customer loyalty," International Journal of Information Management, vol. 31, no. 1, pp. 71-79, 2011.

[58] S. Lee, H. G. Lee, B. Shin, and H. Lee, "Understanding postadoption usage of mobile data services: the role of supplierside variables," Journal of the Association for Information Systems, vol. 10, no. 12, pp. 860-888, 2009.

[59] S. C. Park and S. Y. Ryoo, "An empirical investigation of endusers' switching toward cloud computing: a two factor theory perspective," Computers in Human Behavior, vol. 29, no. 1, pp. 160-170, 2013.

[60] R. T. Cenfetelli and A. Schwarz, "Identifying and testing the inhibitors of technology usage intentions," Information Systems Research, vol. 22, no. 4, pp. 808-823, 2011.

[61] S.-G. Lee, S. H. Chae, and K. M. Cho, "Drivers and inhibitors of SaaS adoption in Korea," International Journal of Information Management, vol. 33, no. 3, pp. 429-440, 2013.

[62] E. M. Rogers, Diffusion of Innovations, University of New Mexico, Albuquerque, New Mexico, 3rd edition, 1983.

[63] Y. Alshamaila, S. Papagiannidis, and F. Li, "Cloud computing adoption by SMEs in the north east of England: a multiperspective framework," Journal of Enterprise Information Management, vol. 26, no. 3, 2004.

[64] A. Gutierrez, E. Boukrami, and R. Lumsden, "Technological, organisational and environmental factors influencing managers' decision to adopt cloud computing in the UK," Journal of Enterprise Information Management, vol. 28, no. 6, 2015.

[65] P. A. Pavlou and D. Gefen, "Building effective online marketplaces with institution-based trust," Information Systems Research, vol. 15, no. 1, pp. 37-59, 2004.

[66] A. Benlian and T. Hess, "Opportunities and risks of softwareas-a-service: findings from a survey of IT executives," Decision Support Systems, vol. 52, no. 1, pp. 232-246, 2012.

[67] R. Schneiderman, "For cloud computing, the sky is the limit [special reports]," IEEE Signal Processing Magazine, vol. 28, no. 1, pp. 15-144, 2011.

[68] N. Li, "The security of cloud computing system enabled by trusted computing technology," in Proceedings of the 2010 2nd International Conference on Signal Processing Systems, IEEE, Dalian, China, July 2011.

[69] A. Elbanna, "Top management support in multiple-project environments: an in-practice view," European Journal of Information Systems, vol. 22, no. 3, pp. 278-294, 2013.

[70] S. Lee and K.-j. Kim, "Factors affecting the implementation success of Internet-based information systems," Computers in Human Behavior, vol. 23, no. 4, pp. 1853-1880, 2007.

[71] M. Bradford and J. Florin, "Examining the role of innovation diffusion factors on the implementation success of enterprise resource planning systems," International Journal of Accounting Information Systems, vol. 4, no. 3, pp. 205-225, 2001. 
[72] K. Zhu and K. L. Kraemer, "Post-adoption variations in usage and value of E-business by organizations: cross-country evidence from the retail industry," Information Systems Research, vol. 16, no. 1, pp. 61-84, 2005.

[73] T. Oliveira and M. F. Martins, "Understanding E-business adoption across industries in European countries," Industrial Management \& Data Systems, vol. 110, no. 9, pp. 1337-1354, 2010.

[74] K. Zhu, K. Kraemer, and S. Xu, "Electronic business adoption by European firms: a cross-country assessment of the facilitators and inhibitors," European Journal of Information Systems, vol. 12, no. 4, pp. 251-268, 2017.

[75] S. C. Misra and A. Mondal, "Identification of a company's suitability for the adoption of cloud computing and modelling its corresponding Return on Investment," Mathematical \& Computer Modelling, vol. 53, no. 3-4, pp. 504-521, 2011.

[76] S. Cai, M. Jun, and Z. Yang, "Implementing supply chain information integration in China: the role of institutional forces and trust $\star$, Journal of Operations Management, vol. 28, no. 3, pp. 257-268, 2010.

[77] C. L. Luk, O. H. M. Yau, L. Y. M. Sin, A. C. B. Tse, R. P. M. Chow, and J. S. Y. Lee, "The effects of social capital and organizational innovativeness in different institutional contexts," Journal of International Business Studies, vol. 39, 2008.

[78] N. Wang, Y. Xue, H. Liang, Z. Wang, and S. Ge, “The dual roles of the government in cloud computing assimilation: an empirical study in China," Information Technology \& People, vol. 32, no. 1, pp. 147-170, 2019.

[79] T. Heart, "Who is out there?" ACM SIGMIS Database: The Database for Advances in Information Systems, vol. 41, no. 3, pp. 49-68, 2010.

[80] J. Repschlaeger, K. Erek, and R. Zarnekow, "Cloud computing adoption: an empirical study of customer preferences among start-up companies," Electronic Markets, vol. 23, no. 2, pp. 115-148, 2013.

[81] J. Fang, Y. Shao, and C. Wen, “Transactional quality, relational quality, and consumer e-loyalty: evidence from SEM and fsQCA," International Journal of Information Management, vol. 36, no. 6, pp. 1205-1217, 2016.

[82] Y. Liu, J. Mezei, V. Kostakos, and H. Li, “Applying configurational analysis to IS behavioural research: a methodological alternative for modelling combinatorial complexities," Information Systems Journal, vol. 27, no. 1, pp. 59-89, 2017.

[83] I. O. Pappas, S. Papavlasopoulou, P. Mikalef, and M. N. Giannakos, "Identifying the combinations of motivations and emotions for creating satisfied users in SNSs: an fsQCA approach," International Journal of Information Management, vol. 53, Article ID 102128, 2020.

[84] P. Reyes-Mercado, "Adoption of fitness wearables: insights from partial least squares and qualitative comparative analysis," Journal of Systems and Information Technology: JSIT, vol. 20, no. 1, 2018.

[85] H. P. Fu, T. H. Chang, T. S. Chang, and L. C. Liu, "Factor analysis on enterprises adopting cloud computing," in Proceedings of the International Conference on Communications, Shanghai, China, September 2016.

[86] R. MacCallum, "Model specification: procedures, strategies, and related issues," 1995.

[87] M. Sarstedt, C. M. Ringle, and J. F. Hair, Partial Least Squares Structural Equation Modeling, Springer International Publishing, Berlin, Germany, 2017. 